\title{
Future legislation
}

\author{
B. SHEERMAN \\ Parliamentary Advisory Council for Transport Safety (PACTS)
}

I offer the following 'shopping list' of national and European legislative measures, which could be implemented in the short to medium term, and suggestions for some institutional changes to strengthen efforts to improve road safety.

\section{Rear seat-belts}

The first stage in this process is now in hand with the Department of Transport consultation on mandatory fitting, although we must continue to advise that the minimum requirement of two outer lap/diagonals in cars with three rear seats is stipulated in the regulations. The second is the retrospective fitting of rear belts in all cars manufactured after October 1981.

\section{Steering wheel design}

The disproportionate increase in head and facial injuries among drivers reported in the study confirms predictions made in the past about the risk of restrained driver head and facial contact with steering wheels. It is clear that if the full potential of seat-belts to protect against head, face and chest injury is to be realized, then not only will seat-belt design need further improvement, but also the current ECE and EEC specifications on steering-system performance.

\section{Laminated windscreens}

The safety benefits of laminated-over toughened windscreens are accepted by the majority of accident researchers and clinical experts. While there has been a very significant reduction in serious eye injuries since the introduction of compulsory seat-belt wearing, protection for unrestrained rear- and front-seat occupants should not be forgotten.

\section{Side-impact protection}

Around $33 \%$ of fatal car accidents involve side impacts and comprise many of the impacts in which seat-belts could not be expected to provide full protection. At present the side structures of cars do not have to conform to any safety standard. It is essential that the high priority is given to reaching agreement on a European specification.

\section{HGV front under-run protection}

Further protection for restrained car occupants would be available through the mandatory fitment of energy absorbing front under-run guards to HGVs (heavy goods vehicles). Research at the Transport and Road Research Laboratory (TRRL) indicates that $65 \%$ of all under-runs in $\mathrm{HGV} /$ car impacts are frontal, and that energy-absorbing front under-run guards could potentially save around 60 car-occupant fatalities every year.

\section{Head-restraints}

The potential of appropriately positioned head-restraints in reducing hyper-extension injuries is

Correspondence: Barry Sheerman, MP, Co-Chairman, Parliamentary Advisory Council for Transport Safety, House of Commons, Westminster, London, England. 
generally acknowledged. Amendments to the height specification in the UN ECE agreement seem essential before advising on a national or European legislation.

\section{Two-wheeled motor-vehicle rider protection}

Motorcycles are ten times more likely to be involved in an injury-producing accident per mile travelled than cars, and are also most frequently involved as the 'striking object' in serious and fatal pedestrian accidents. National policy, to date, has tended to rely upon education, training and licensing as means of attempting to prevent accidents. There are, however, a number of engineering measures which research has indicated as having accident avoidance potential and which, if adopted, would usefully supplement current policy:

- daytime running lights;

- anti-lock braking systems;

- leg-protecting devices.

\section{Pedal cyclist and pedestrian}

While many of the road-safety measures which may benefit pedestrians and cyclists fall under the umbrella of local authority responsibility, legislators at national level do have a duty in determining the amount of resources available to allow maximum effectiveness. The following areas seem particularly deserving of an increased allocation of resources, both in terms of staff and monies:

\section{Road safety education}

Increased resources for primary, secondary and tertiary road-safety education, and an increase i⿺辶卬 the Department of Education and Science's Road Safety Inspectorate in schools.

\section{Small engineering schemes for accident reduction}

The need for encouragement to local highway authorities via a specific allocation of resources to implement low-cost highway engineering schemes for accident reduction.

\section{Traffic regulation enforcement}

Additional manpower to increase the level of traffic regulation enforcement in areas of high traffic density.

\section{Street lighting}

Improved provision of street lighting in residential areas.

\section{Measures to improve safety in residential areas}

Road safety measures tend to be undertaken on roads with a high traffic-density or where accidents most often occur. On residential roads, accidents are spread thinly over a large road network and often the need for preventive measures seems less apparent. The accident rate on unclassified routes, however, is significantly higher than those rates for Class A or B roads (Department of Transport, 1984) and the majority of child pedestrian accidents occur within ${ }_{2}$ $400 \mathrm{~m}$ from home (Bennett \& Marland, 1978). While the TRRL are conducting research into the potential for an area-wide strategic approach in such areas, a look at overseas research, in the meantime, does suggest that legislation may have a considerable contribution to make. Accident 
investigations in the Netherlands indicate that 'woonerven' or residential streets with priority to pedestrians and pedal cyclists may have a very positive effect on accident reduction. A review of the evidence by SWOV suggests that savings of the order of $50 \%$ have been achieved (Kraay et al., 1985).

In view of the relationship between speed and accidents and the need to keep speeds down in residential areas, the establishment of a hierarchy of speeds in urban areas seems appropriate to supplement speed control measures of the engineering type. In some cases, the current 30 -mph speed limit is probably far too high and a review of the potential benefits of a revised framework is desirable.

\section{Measures to reduce the incidence of drinking and driving}

With $10 \%$ of all injury accidents and $33 \%$ of all fatal injuries to drivers and motorcycle riders involving excess alcohol in Britain each year (Transport and Road Research Laboratory, 1983), then further action is clearly necessary.

\section{The legal limit}

The identification and treatment of the 'high risk' offender is another area in which we have yet to make significant inroads. Two thirds of second excess alcohol offenders and half of first offenders are detected with Blood Alcohol Concentration (BAC) levels of over $150 \mathrm{mg} / 100 \mathrm{ml}$.

\section{A national transport safety board}

I suggest that an effectively organized national research framework must be independent of Government in assessing needs and evaluating effects.

\section{Parliamentary select committee on transport safety}

A glance at the experience in New South Wales, Australia suggests a further valuable institutional development in the setting up of a Parliamentary Committee on Transport Safety, which, among other functions, could be influential in the resources debate. A national transport safety board focusing and directing effort in all areas, as well as reporting to this Parliamentary Committee on a regular basis, could, indeed, provide the kind of institutional framework which could herald a new era of transport policy implementation.

\section{POINTS RAISED IN OPEN DISCUSSION}

- Exemption from the seat belt law, e.g. for taxi drivers, should be reviewed and many classes should no longer be exempt.

- Local authorities could be given greater powers to enforce 'local' safety measures.

- Doubt has been expressed by a car manufacturer that the case for compulsory head restraints was proven.

\section{REFERENCES}

Department of Transport (1984) Road Accidents Great Britain, 1983. London: Her Majesty's Stationery Office.

Bennett, G. T. \& Marland J. (1978) Road Accidents in Traditionally Designed Local Authority Estates. Crowthorne: DOE, DTp \& TRRL Report SR 394.

Kraay, J. H., Mathijssen M. P. M. \& Wegman F. C. M. (1985) Towards Safer Residential Areas. Netherlands: Institute for Road Safety Research, SWOV/Ministry of Transport.

Transport \& Road Research Laboratory (1983) The Facts about Drinking and Driving. Crowthorne: TRRL. 